\title{
The Late Effect of Grenade Fragments
}

\author{
Maj R P Symonds \\ TD, MD, MRCP, FRCR, RAMC (V) \\ RMO 3 Bn 51 Highland Volunteers (The Argyll and Sutherland Highlanders)
}

C Mackay

BSC, MB, FRCS (England, Edinburgh and Glasgow)

Consultant Surgeon, Gartnavel Hospital and Western Infirmary Glasgow

P Morley

$M B, D M R D, F R C R, M R C P(G)$

Consultant Radiologist, Western Infirmary Glasgow

SUMMARY: Following the explosion of a grenade or shell, the victim may be peppered with literally hundreds of piec $\vec{f}$ of metal. Troublesome fragments which perforate a major viscus may be removed but others are of ten left behind, acit $N$ felt ( usually correctly) that these fragments will cause no harm. We describe a case in which a grenade fragment receō ca

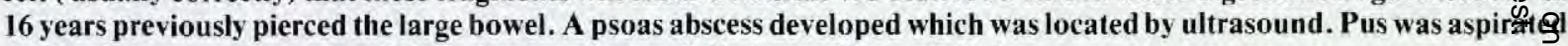
under ultrasound control and the lesion was successfully treated by antiobitics.

\section{Case Report}

The patient was 38 years of age at the time of his recent illness, 16 years before in Aden he was injured by a hand grenade and received multiple wounds, mainly to the left side of body. The lower pole of the left kidney was perforated and bled profusely into the retroperitoneal space. There was a through-and-through perforation of the descending colon. The fragments causing these injuries were not found. There were also four wounds in the right thigh, two wounds in the left thigh, one in the right ankle and one in the left calf which were excised and treated by delayed primary suture. The perforated segment of colon was exenterated and a temporary colostomy was performed. Recovery from these injuries appeared to be complete.

10 years later the patient had an emergency pyloroplasty and vagotomy for a bleeding duodenal ulcer. The operation was difficult because of adhesions. He remained well for 6 years and then developed pain in the left hip which radiated down to the knee. The pain gradually increased in intensity. After two weeks, the patient found he could ease the pain by flexing the hip and complained of a new pain in the back. Palpitation of the left loin was painful as was extension of the left hip. The W.B.C. count was $18.9 \times 10^{9} 1$ and the E.S.R. was 120 . A radiograph of abdomen showed numerous metallic fragments in the abdomen and the psoas outline looked indistinct. The clinical diagnosis of a pyogenic psoas abscess was confirmed by an ultrasound scan (see figure 1). Under ultrasound control, a small volume of very thick pus was aspirated through a 20 gauge spinal needle. Bacteroides

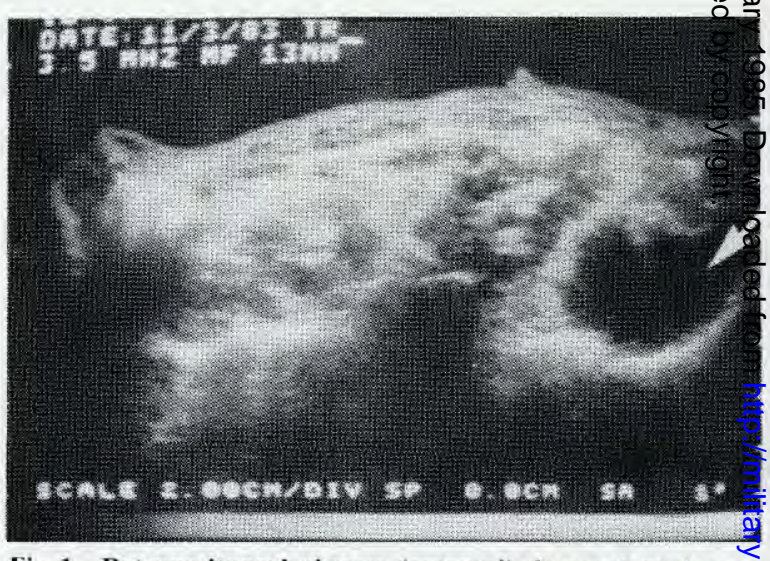

Fig 1 Retroperitoneal abscess (arrowed) demonstrated on transverse ultrasound scan of left iliac fossa.

fragilis was grown from the pus. Metronidazole $400 \mathrm{mg}$ t.i.d. was given by mouth for 10 days. After 5 days thet. patient's pain was less, the W.B.C. count had fallen to $11.3 \times 10^{9} 1$ and the abscess was half the original size

One month later he was totally asymptomatic and hag returned to duty although a further ultrasound examinas tion showed persistence of the abscess cavity which wa smaller and less clearly defined suggesting further resolution.

The patient continues to serve in the Regular Army i an unrestricted medical category and has had no furthe problems from his multiple metal fragments during the last 20 months. 


\section{Discussion}

It is classical surgical teaching that the abdomen should not be explored to find sterile grenade fragments. Such teaching is based on sound experience, as dense connective tissue tends to form around metallic bodies preventing further problems.'

Projectiles, such as bullets can lodge in vital organs, such as the heart for many years without causing problems. In 1941, Grey Turner ${ }^{2}$ described a patient who had been under his care for 23 years with a machine gun bullet in the heart. The same paper describes a specimen in the Royal Army Medical College at Millbank. The heart was removed from a soldier who had died in 1874 in Ashante from remittant fever. He had been shot in the chest while serving in New Zealand in 1860 and had made a full recovery. A musket ball was lodged at the root of the great vessels and caused no problem during life. Occasionally problems can develop years after the initial injury $^{3}$ as in this case. The clinical presentation as an acute psoas abscess however, was very unusual. Ultra- sound proved to be a most useful technique confirming the diagnosis and aiding aspiration to obtain pus for culture. Surgical excision of the of fending fragment would have been difficult owing to the extensive adhesions from previous operations and may have resulted in the excision of a long length of colon. Aspiration of pus and suitable antibiotics was a preferable treatment. The psoas abscess was treated 20 months ago. Hopefully the splinter is now surrounded by fibrous tissue and will cause no further problem.

\section{Acknowledgement}

To Colonel "Paddy" MacMahon, Comd Med, Scotland, who suggested we publish this case, and to Mrs M A Wilmoth, who typed the manuscript.

\section{REFERENCES}

1. Davis AND Christopher's Text-book of Surgery Ed Sabistan D C pp 867 Saunders, London 1977.

2. GREY TURNER G "A Bullet in the Heart for 23 years" Surgery $1941 ; 9 ; 832-852$.

3. BARRetT $N$ R "Foreign Bodies in the Cardiovascular System" Br J Surg 1950; 37; 416-455.

\section{NOTICE}

Would subscribers to the Journal please ensure that the Journal Office is notified as soon as possible of any change of address. This would reduce the amount of time wasted trying to trace new addresses. 